EXTENDED REPORT

\title{
Prevalence of anti-cyclic citrullinated peptide and anti-keratin antibodies in patients with primary Sjögren's syndrome
}

\author{
J-E Gottenberg, S Mignot, P Nicaise-Rolland, J Cohen-Solal, F Aucouturier, J Goetz, \\ C Labarre, O Meyer, J Sibilia, X Mariette
}

See end of article for authors' affiliations

\section{Correspondence to:}

Professor Xavier Mariette, Service de Rhumatologie, Hôpital de Bicêtre, 78 rue du Général Leclerc, 94275 Le Kremlin Bicêtre, France; xavier.mariette@bct.aphop-paris.fr

Accepted 25 March 2004 Published Online First 1 July 2004
Objective: To investigate the prevalence of anti-cyclic citrullinated peptide (anti-CCP) and anti-keratin antibodies (AKA) in patients with primary Sjögren's syndrome.

Methods: 149 patients with a diagnosis of primary Siögren's syndrome according to the European/ American consensus criteria were recruited from three French medical centres. The presence of anti-CCP was determined by enzyme linked immunosorbent assay and of AKA antibodies by indirect immunofluorescence. Radiographs of hands and feet were evaluated at the time of anti-CCP analysis.

Results: Six patients with radiological erosions and nine patients with non-erosive arthritis fulfilling ACR criteria for rheumatoid arthritis were thought to have rheumatoid arthritis and secondary Siögren's syndrome, while 134 were considered to have primary Sjögren's syndrome (mean (SD) disease duration, 11.1 (6.6) years). Of these, 80 tested positive for $\lg M$ rheumatoid factor (RF) (59\%), 10 (7.5\%) for antiCCP, $7(5.2 \%)$ for AKA, and $5(3.7 \%)$ for both anti-CCP and AKA. There was no difference in clinical and biological features, including prevalence of RF, between anti-CCP positive and negative patients. The nine Sjögren patients with non-erosive arthritis, fulfilling ACR criteria for rheumatoid arthritis, were all CCP positive. Their response to disease modifying antirheumatic drugs could be different from classical rheumatoid patients.

Conclusions: Most patients with primary Siögren's syndrome are negative for AKA and anti-CCP, but positive test results should not rule out this diagnosis. Anti-CCP positive patients, who may be prone to developing rheumatoid arthritis, require cautious clinical and radiographic follow up.
A nti-cyclic citrullinated peptide antibody (anti-CCP) has proved to be an efficient diagnostic marker for the diagnosis of rheumatoid arthritis. ${ }^{12}$ Both anti-CCP and the so called anti-keratin antibodies (AKA), which recognise the protein filaggrin in rat oesophageal mucosal cells, specifically bind to substrates containing the modified amino acid citrulline. ${ }^{3}$ Numerous studies have corroborated the high specificity (more than 95\%) of the anti-CCP assay for the diagnosis of rheumatoid arthritis. ${ }^{12}$ However, the control sera used to assess the discriminative characteristics of this assay were mostly derived from normal subjects, patients with infectious diseases, or cohorts of patients with a large variety of rheumatic diseases. Primary Sjögren's syndrome was barely represented in the latter cohorts. However, the clinical manifestations of Sjögren's syndrome and rheumatoid arthritis may be very similar, and the prevalence of rheumatoid factor (RF) is the same in the two conditions. In addition, polyclonal $\mathrm{B}$ activation and autoantibody synthesis is a hallmark of primary Sjögren's syndrome. As little is known about the presence of anti-CCP and AKA in this condition, we investigated their prevalence in a cohort of patients with a diagnosis of primary Sjögren's syndrome according to the American-European Consensus Group criteria (which involve a focus score of $\geqslant 1$ on a labial salivary gland biopsy or the presence of anti-SSA or anti-SSB antibodies). ${ }^{4}$

\section{METHODS}

Patients

We recruited 149 patients from the Department of Rheumatology, Bicêtre Hospital, Le Kremlin Bicêtre,
Hautepierre Hospital, Strasbourg, and Bichat Hospital, Paris, between October 2001 and June 2003. All patients fulfilled the diagnostic criteria for primary Sjögren's syndrome according to the American-European Consensus Group. Each patient was clinically assessed for the presence of synovitis and extraglandular involvement (including lung, kidney, and skin involvement, vasculitis, neuropathy, and lymphoma). The American College of Rheumatology (ACR) classification criteria for rheumatoid arthritis were assessed in each patient and the patients who fulfilled four or more of these criteria were considered to have rheumatoid arthritis with secondary Sjögren's syndrome and were analysed separately.

\section{Determination of antibodies \\ Antikeratin antibodies}

IgG AKA were determined by two senior seroimmunologists using indirect immunofluorescence (IFI) as described by Young et al. ${ }^{5}$ Serum samples were diluted 1:10. Positive sera were titrated, and the greatest serum dilution showing fluorescence was considered the titration end point.

In the case of discordant results the same sera were reanalysed by one of us (PNR) for a second independent determination using the same technique.

Anti-cyclic citrullinated peptide antibodies A second generation anti-CCP assay (CCP2) was carried out using an enzyme linked immunosorbent assay (ELISA)

Abbreviations: ACR, American College of Rheumatology; AKA, antikeratin antibodies; anti-CCP, anti-cyclic citrullinated peptide antibodies; DMARD, disease modifying antirheumatic drug; RF, rheumatoid factor 
(Immunoscan RA, Eurodiagnostica Arnhem, Netherlands), according to the manufacturer's instructions. Patient serum samples were diluted 1:50 and were considered positive if the antibody titre was greater than 50 arbitrary units, as determined by dilution of a positive standard serum. Sera with intermediate positivity according to the manufacturer (with titres between 25 and 50 units) were considered negative for anti-CCP.

As for AKA, in the case of discordant results the sera were reanalysed using the same technique.

\section{Rheumatoid factor}

IgM RF was determined by nephelometry and was considered positive at $\geqslant 20 \mathrm{IU} / \mathrm{ml}$.

\section{Siögren's syndrome antibodies}

Anti-Ro(SSA)/La(SSB) were detected by the commercial ELISA assay (Varelisa Ro and La antibodies, PharmaciaUpjohn, Freiburg, Germany), which used baculovirus expressed recombinant Ro52 and Ro60, coated in an unspecified ratio. All the positive results were confirmed by either counterimmunoelectrophoresis using purified antigens obtained from rabbit and rat thymus powder (Pel Freez, Arkansas, USA) and from human spleen extract (Laboratoire d'Immuno-Pathologie, Hôpital Saint-Louis, Paris, France), or by double radial immunodiffusion.

\section{Radiographic measurements}

Radiographs of the hands and feet were taken in all patients at the time of anti-CCP analysis. If erosions were present, the diagnosis of primary Sjögren's syndrome was discarded and the patient was considered to have rheumatoid arthritis with secondary Sjögren's syndrome. Such patients $(n=6)$ were excluded from the study. The radiographs of all patients were reviewed by two senior rheumatologists.

\section{Statistical analysis}

The $\chi^{2}$ test (with Yates's correction when appropriate) and Student's $t$ test were used for testing the significance of differences in baseline variables between anti-CCP positive and anti-CCP negative patients. All tests were two sided, and probability (p) values of less than 0.05 were considered significant.

\section{RESULTS}

\section{Patient characteristics}

Six patients with radiological erosions were considered to have rheumatoid arthritis with secondary Sjögren's syndrome. Nine further patients without erosions who fulfilled the ACR classification criteria for rheumatoid arthritis were analysed separately. Thus the study involved 134 patients with primary Sjögren's syndrome ( 12 men and 122 women) who did not fulfil the ACR criteria for rheumatoid arthritis. Their mean (SD) age was 56.4 (13.6) years and their mean disease duration was 11.1 (6.6) years (range 1 to 27). AntiSSA activity was present in 79 patients $(59 \%)$ and anti-SSB in 50 patients $(37.3 \%)$. The focus score was $\geqslant 1$ in 105 patients $(78.3 \%)$. Synovitis and extraglandular involvement was observed in $36(26.9 \%)$ and 51 (38\%) patients, respectively.

\section{Prevalence of anti-CCP, AKA, rheumatoid factor, and cryoglobulinaemia}

Ten samples (7.5\%) tested positive for anti-CCP2 antibodies at $>50$ units reactivity, including eight $(5.9 \%)$ at $>100$ units. The mean (SD) value of the anti-CCP titre was 623.8 (584.8) in positive sera. Five samples in which the titre was between 25 and 50 units after two independent assays were considered negative for anti-CCP. AKA were detected in seven patients $(5.2 \%)$. Five patients $(3.7 \%)$ tested positive for both anti-CCP antibodies and AKA. Five patients had positive anti-CCP test results but negative AKA, while two patients had only positive AKA. A second determination using the same techniques confirmed the discordant results for AKA and anti-CCP results in these seven patients. Of the $80 \operatorname{IgM}$ RF positive sera $(59.7 \%)$, seven $(8.7 \%)$ were positive for antiCCP, six $(7.5 \%)$ for AKA, and four $(5 \%)$ for both anti-CCP and AKA. Cryoglobulinaemia was detected in seven patients whose sera were all negative for anti-CCP and AKA.

\section{Characteristics of anti-CCP positive patients}

Clinical and biological features of the 10 anti-CCP positive patients with primary Sjögren's syndrome are summarised in table 1 . Three patients were treated with disease modifying antirheumatic drugs (DMARDs) (two with methotrexate, one with hydroxychloroquine).

Demographic factors, including age and disease duration, were not significantly different between anti-CCP positive and anti-CCP negative patients (table 2). Neither the presence of synovitis nor extraglandular involvement was associated with the presence of anti-CCP or AKA (table 2).

Mean serum IgG did not differ significantly between the anti-CCP positive and anti-CCP negative groups, nor did the erythrocyte sedimentation rate, the presence of anti-SSA, anti-SSB, or RF, or a focus score of $\geqslant 1$ (table 2 ).

\section{DISCUSSION}

In this cohort of 134 patients with primary Sjögren's syndrome, none of whom fulfilled the ACR classification criteria for rheumatoid arthritis, $7.5 \%$ and $5.2 \%$ of the sera were positive for anti-CCP and AKA, respectively. In comparison, the prevalence of anti-CCP was $68.9 \%$ in patients with rheumatoid arthritis, using the same second generation

Table 1 Clinical and biological features of patients with primary Sjögren's syndrome who were positive for anti-cyclic citrullinated peptide antibodies

\begin{tabular}{|c|c|c|c|c|c|c|c|c|c|c|}
\hline Patient & $\begin{array}{l}\text { Age } \\
\text { (years) }\end{array}$ & $\begin{array}{l}\text { Disease duration } \\
\text { (years) }\end{array}$ & $\begin{array}{l}\text { Synovitis } \\
(\mathrm{Y} / \mathrm{N})\end{array}$ & $\begin{array}{l}\text { Extraglandular } \\
\text { involvement }(\mathrm{Y} / \mathrm{N})\end{array}$ & $\begin{array}{l}\text { ESR } \\
(\mathrm{mm})\end{array}$ & $\begin{array}{l}\text { Serum IgG } \\
\text { (g/l) }\end{array}$ & $\begin{array}{l}\text { AKA } \\
(\mathrm{Y} / \mathrm{N})\end{array}$ & $\begin{array}{l}\text { RF } \\
(\mathrm{Y} / \mathrm{N})\end{array}$ & $\begin{array}{l}\text { Anti-SSA/anti- } \\
\text { SSB }(Y / N)\end{array}$ & $\begin{array}{l}\text { Focus score } \\
\geqslant 1(\mathrm{Y} / \mathrm{N})\end{array}$ \\
\hline 1 & 38 & 10 & $N$ & $\mathrm{~N}$ & 3 & 12.3 & $N$ & $\mathrm{~N}$ & $\mathrm{Y} / \mathrm{N}$ & $Y$ \\
\hline 2 & 33 & 2 & $Y$ & $Y$ & 76 & 18.1 & $Y$ & $Y$ & $\mathrm{~N} / \mathrm{N}$ & $Y$ \\
\hline 3 & 64 & 23 & $Y$ & $Y$ & 10 & 11.2 & $Y$ & $Y$ & $Y / Y$ & $Y$ \\
\hline 4 & 54 & 7 & $N$ & $\mathrm{~N}$ & 40 & 19.4 & $N$ & $N$ & $Y / Y$ & $N$ \\
\hline 5 & 35 & 8 & $N$ & $N$ & 7 & 9.7 & $N$ & $N$ & $Y / Y$ & $Y$ \\
\hline 6 & 53 & 8 & $N$ & $\mathrm{~N}$ & 45 & 15.7 & $Y$ & $Y$ & $\mathrm{~N} / \mathrm{N}$ & $Y$ \\
\hline 7 & 55 & 14 & $N$ & $\mathrm{~N}$ & 41 & 39 & $Y$ & $Y$ & $\mathrm{Y} / \mathrm{N}$ & $\mathrm{N}$ \\
\hline 8 & 65 & 8 & $\mathrm{~N}$ & $N$ & 30 & 11.4 & $N$ & $Y$ & $\mathrm{~N} / \mathrm{N}$ & $Y$ \\
\hline 9 & 43 & 14 & $\mathrm{~N}$ & $N$ & 32 & NA & $Y$ & $Y$ & $\mathrm{Y} / \mathrm{N}$ & $Y$ \\
\hline 10 & 55 & 7 & $\mathrm{~N}$ & $N$ & 27 & NA & $N$ & $Y$ & $\mathrm{~N} / \mathrm{N}$ & $Y$ \\
\hline
\end{tabular}

AKA, anti-keratin antibodies; NA: not assessed; RF, rheumatoid factor; SSA/B, Sï̈gren's syndrome antibodies, type A/type B; Y/N: yes (present)/no (absent). 
Table 2 Characteristics of the study population

\begin{tabular}{lllc}
\hline & $\begin{array}{l}\text { Anti-CCP } \\
\text { positive } \\
\text { patients } \\
\text { (n= 10) }\end{array}$ & $\begin{array}{l}\text { Anti-CCP } \\
\text { negative } \\
\text { patients } \\
(\mathbf{n}=124)\end{array}$ & p Value \\
Variable & $49.5(11.5)$ & $56.8(13.7)$ & 0.11 \\
\hline Age (years) & $10.1(5.7)$ & $11.0(6.7)$ & 0.65 \\
Disease duration (years) & $2(20 \%)$ & $34(27.4 \%)$ & $0.9^{*}$ \\
Synovitis & & & \\
Extraglandular & $2(20 \%)$ & $49(39.5 \%)$ & $0.5^{*}$ \\
involvement & $31.1(22.1)$ & $32.1(27.7)$ & 0.91 \\
ESR (mm/h) & $17.1(9.5)$ & $16.6(8.2)$ & 0.87 \\
Serum lgG (g/l) & $5(50 \%)$ & $2(1.6 \%)$ & $<0.001^{*}$ \\
AKA & $7(70 \%)$ & $73(58.9 \%)$ & $0.9^{*}$ \\
Rheumatoid factor & $6(60 \%)$ & $73(58.9 \%)$ & $>0.9^{*}$ \\
Anti-SSA & $3(30 \%)$ & $47(37.9 \%)$ & $>0.9^{*}$ \\
Anti-SSB & $8(80 \%)$ & $97(78.2 \%)$ & $>0.9^{*}$ \\
Focus score $\geqslant 1$ & & \\
\hline Values are mean (SD) nor $\mathrm{n}(\%)$. & \\
*Value with Yates' correction. & & \\
AKA, anti-keratin antibodies; anti-CCP, anti-cyclic citrullinated peptide \\
antibodies; ESR, erythrocyte sedimentation rate; IgG, immunoglobulin G; \\
SSA/B, Siögren's syndrome antibodies, type A/type B \\
\hline
\end{tabular}

anti-CCP assay (Nicaise-Rolland $\mathrm{P}$ et al, unpublished data). To our knowledge, this is the first study to analyse the prevalence of anti-CCP and AKA in a cohort of patients with primary Sjögren's syndrome according to the AmericanEuropean consensus group criteria. This population study compares well with other published reports of patients with primary Sjögren's syndrome with respect to their clinical and immunological features. ${ }^{6}$

Interestingly, the mean titre of anti-CCP was high and no positive serum had borderline values. Eight of the 10 positive sera ( $5.9 \%$ of patients) had a reactivity greater than 100 units, a threshold which definitely decreases the risk of false positive results when using the second generation assay. The mean age of patients and mean disease duration were similar between patients with and without anti-CCP. Hypergammaglobulinaemia could not account for the positive anti-CCP test results, as the mean serum IgG did not vary significantly according to anti-CCP status.

Our study confirms that anti-CCP and AKA may be detected in patients with no radiographic evidence of erosions after a long follow up. This dissociation has already been reported in patients with rheumatoid arthritis. ${ }^{78}$

Might anti-CCP positive patients in fact be suffering from rheumatoid arthritis? First, the long period of disease duration without erosions ( 10 years) does not support a current diagnosis of rheumatoid arthritis associated with secondary Sjögren's syndrome. Second, anti-SSB prevalence was the same in patients with and without anti-CCP, whereas the frequency of anti-SSB is usually lower in secondary Sjögren's syndrome. ${ }^{9}$ Finally, we chose to exclude the 15 patients who fulfilled the ACR classification criteria for rheumatoid arthritis, in order to be as stringent as possible in our definition of primary Sjögren's syndrome. However, while it is quite certain that the six patients with erosions had rheumatoid arthritis with secondary Sjögren's syndrome, the diagnosis of the nine others remains debatable. Indeed, while they fulfilled ACR classification criteria for rheumatoid arthritis because they had RF positive symmetrical polyarthritis, they had not developed erosions after a long period of follow up (mean disease duration nine years) and were previously considered to have primary Sjögren's syndrome by their physicians. Moreover, six of these nine patients had been treated with DMARDs, but without any response. It is noteworthy that the authors of the classification criteria for rheumatoid arthritis acknowledged that "primary Sjögren's syndrome patients with arthritis could cause classification difficulties and required further study". ${ }^{10}$ All these nine patients were anti-CCP positive. This can be interpreted as an additional marker of definite rheumatoid arthritis or as an argument for the possibly higher prevalence of anti-CCP and AKA in Sjögren's syndrome in daily clinical practice than that observed in the present study. HLA genotyping could help to differentiate primary Sjögren's syndrome with polyarthritis and anti-CCP from rheumatoid arthritis, as HLA-DR3 is associated with primary Sjögren's syndrome and the presence of anti-SSB antibody, ${ }^{11}$ whereas HLA-DR4 predisposes to rheumatoid arthritis and could be required for the presentation of citrullinated antigens. ${ }^{12}$ Further studies are needed to evaluate the effect of DMARDs in this subpopulation of patients fulfilling ACR criteria for rheumatoid arthritis but presenting with non-erosive arthritis like patients with primary Sjögren's syndrome.

The possibility that patients with anti-CCP antibodies could be prone to develop rheumatoid arthritis cannot be ruled out. It is known that anti-CCP can be present years before the first signs of rheumatoid arthritis. ${ }^{13}$ In three antiCCP positive patients with polysynovitis, the use of DMARDs might have prevented progression to rheumatoid arthritis. Additionally, the concomitant presence of IgM RF and antiCCP, which was observed in seven patients, is the best predictor of the development of active rheumatoid arthritis. ${ }^{14}$ Thus a cautious clinical and radiographic follow up is required to confirm the absence of evolution to rheumatoid arthritis in anti-CCP positive patients.

Nevertheless, this study suggests that the production of anti-CCP antibodies, which have also been reported recently in patients with juvenile idiopathic arthritis, ${ }^{15}$ could be less intimately related to the pathogenesis of rheumatoid arthritis than was previously hypothesised. Polyclonal activation of B lymphocytes-a predominant feature of primary Sjögren's syndrome-might account for the presence of anti-CCP and AKA. Likewise, an increased serum level of BLyS, a potent B lymphocyte co-stimulation molecule, is associated with raised serum $\gamma$ globulin, RF, and anti-SSA/SSB in patients with Sjögren's syndrome. ${ }^{16}$

\section{Conclusions}

Most patients with primary Sjögren's syndrome are negative for AKA and anti-CCP. However, clinicians should be aware that the presence of anti-CCP or AKA does not rule out the diagnosis of primary Sjögren's syndrome, as 7.5\% of affected patients not fulfilling ACR criteria for rheumatoid arthritis were anti-CCP positive. Moreover, we identified another group of anti-CCP positive patients with Sjögren's syndrome fulfilling ACR classification criteria for rheumatoid arthritis but with non-erosive arthritis, whose response to DMARDs appeared to be different from classical rheumatoid patients. Anti-CCP positive patients require a cautious clinical and radiographic follow up to confirm that their disease does not evolve into rheumatoid arthritis in the future.

\section{ACKNOWLEDGEMENTS}

We thank Isabelle Marie (Clinical Research Unit, Bicêtre Hospital, AP-HP) for excellent technical assistance. JEG was supported by the Société Française de Rhumatologie and the Fondation pour la Recherche Médicale

\section{Authors' affiliations}

J-E Gottenberg, X Mariette, Department of Rheumatology, Bicêtre Hospital, INSERM EMI 109, Le Kremlin Bicêtre, France

S Mignot, P Nicaise-Rolland, C Labarre, Department of Immunology, Bichat Hospital, Paris

J Cohen-Solal, J Sibilia, Department of Rheumatology, Hautepierre

Hospital, University Hospitals of Strasbourg, Strasbourg, France

F Aucouturier, Department of Immunology and Histocompatibility, SaintLouis Hospital, Paris 
J Goetz, Department of Immunology, Hautepierre Hospital, University Hospitals of Strasbourg

O Meyer, Department of Rheumatology, Bichat Hospital

\section{REFERENCES}

1 Schellekens GA, Visser $H$, de Jong BA, van den Hoogen FH, Hazes JM, Breedveld FC, et al. The diagnostic properties of rheumatoid arthritis antibodies recognizing a cyclic citrullinated peptide. Arthritis Rheum 2000;43:155-63.

2 Bizzaro N, Mazzanti G, Tonutti E, Villalta D, Tozzoli R. Diagnostic accuracy of the anti-citrulline antibody assay for rheumatoid arthritis. Clin Chem 2001;47:1089-93.

3 Sebbag M, Simon M, Vincent C, Masson-Bessiere C, Girbal E, Durieux JJ, et al. The antiperinuclear factor and the so-called antikeratin antibodies are the same rheumatoid arthritis-specific autoantibodies. J Clin Invest 1995; 95:2672-9.

4 Vitali C, Bombardieri S, Jonsson R, Moutsopoulos HM, Alexander EL, Carsons SE, et al. and the European Study Group on Classification Criteria for Siögren's Syndrome. Classification criteria for Siögren's syndromeEuropean Consensus Group. Ann Rheum Dis 2002;61:554-8.

5 Young A, Corbett M, Winfield J, Jaqueremada D, Williams P, Papasavvas G et al. A prognostic index for erosive changes in the hands, feet, and cervica spines in early rheumatoid arthritis. Br J Rheumatol 1988;27:94-101.

6 Pertovaara M, Pukkala E, Laippala P, Miettinen A, Pasternack A. A longitudinal cohort study of Finnish patients with primary Sjogren's syndrome: clinical, immunological, and epidemiological aspects. Ann Rheum Dis 2001:60:467-72

7 Meyer O, Labarre C, Dougados M, Goupille P, Cantagrel A, Dubois A, et al. Anticitrullinated protein/peptide antibody assays in early rheumatoid arthritis for predicting five year radiographic damage. Ann Rheum Dis 2003;62:120-6.
8 Paimela L, Palosuo T, Aho K, Lukka M, Kurki P, Leirisalo-Repo M, et al. Association of autoantibodies to filaggrin with an active disease in early rheumatoid arthritis. Ann Rheum Dis 2001;60:32-5.

9 Manoussakis MN, Tzioufas AG, Pange PJ, Moutsopoulos HM. Serological profiles in subgroups of patients with Sjogren's syndrome. Scand J Rheumatol Suppl 1986;61:89-92

10 Arnett FC, Edworthy SM, Bloch DA, McShane DJ, Fries JF, Cooper NS, et al. The American Rheumatism Association 1987 revised criteria for the classification of rheumatoid arthritis. Arthritis Rheum 1988;31:315-24.

11 Gottenberg JE, Busson M, Loiseau P, Cohen-Solal J, Lepage V, Charron D, et al. In primary Siögren's syndrome, HLA class II is associated exclusively with autoantibody production and spreading of the autoimmune response. Arthritis Rheum 2003;48:2240-5.

12 Hill JA, Southwood S, Sette A, Jevnikar AM, Bell DA, Cairns E. Cutting edge: the conversion of arginine to citrulline allows for a high-affinity peptide interaction with the rheumatoid arthritis-associated HLA-DRB1 *0401 MHC class II molecule. J Immunol 2003;171:538-41.

13 Rantapaa-Dahlqvist SR, de Jong BA, Berglin E, Hallmans G, Wadell G, Stenlund $\mathrm{H}$, et al. Antibodies against citrullinated peptides and $\lg \mathrm{A}$ rheumatoid factor predict the development of rheumatoid arthritis. Arthritis Rheum 2003;48:2741-9.

14 Vencovsky J, Machacek S, Sedova L, Kafkova J, Gatterova J, Pesakova V, et al. Autoantibodies can be prognostic markers of an erosive disease in early rheumatoid arthritis. Ann Rheum Dis 2003;62:427-30.

15 van Rossum $M$, van Soesbergen $R$, de Kort $S$, ten Cate $R$, Zwinderman AH, de Jong B, et al. Anti-cyclic citrullinated peptide (anti-CCP) antibodies in children with juvenile idiopathic arthritis. J Rheumatol 2003;30:825-8.

16 Mariette X, Roux S, Zhang J, Bengoufa D, Lavie F, Zhou T, et al. The level of BLyS (BAFF) correlates with the titre of autoantibodies in human Sjogren's syndrome. Ann Rheum Dis 2003;62:168-71. 